\title{
ELECTROPHYSICAL CHARACTERISTICS OF THE NEAR-SURFACE LAYER OF SEMICONDUCTOR CERAMICS FOR ZnO VARISTORS
}

\author{
R. I. Lavrov, V. R. Kolbunov", V. F. Bashev \\ Oles Honchar Dnipro National University, Dnipro, Ukraine \\ *e-mail: kolbunov_vadim@i.ua
}

\begin{abstract}
Electrophysical properties of near-surface layer of $\mathrm{ZnO}$ varistor ceramics forming during hightemperature annealing in oxidizing gaseous atmosphere are studied. Microstructure of near-surface layer and its electrical properties have features which are determined by an increased concentration of oxygen at surface of pressed ceramic billets in comparison with bulk during annealing. From the data of electron raster microscopy of cross-chipping of varistors, it is defined that the average value of thickness of nearsurface layer is $40 \mu \mathrm{m}$. It is found that the specific resistivity value of near-surface layer is $5.3 \cdot 10^{12} \Omega \cdot \mathrm{cm}$. The electrical capacitance of near-surface layer is calculated from capacitance measurement data for varistors containing such layer under two electrodes and without layers. It is shown that the electrical capacitance of near-surface layer exceeds that of varistor by more than an order. Conclusion is made that the near-surface layer gives a weak contribution to dielectric properties of $\mathrm{ZnO}$ varistor ceramics. However contribution of this layer to electrical conductivity of ceramics in pre-breakdown region is significant.

Keywords: varistor, zinc oxide ceramics, near-surface layer, electric resistivity.
\end{abstract}

Received 15.09.2018; Received in revised form 12.10.2018; Accepted 15.11.2018

\section{Introduction}

Zinc-oxide varistors are used in devices for limiting the overvoltage on electrical circuits, electronic equipment and schemes [1-5]. Volt-current characteristics (VCC) of ZnO varistors in the range of electric currents of $\left(10^{-3}-1\right) \mathrm{A} \cdot \mathrm{cm}^{-2}$ exhibits high nonlinearity. At low strengths of electrical field (in the region of Ohm's law) varistor resistance is high (of order of $10^{10}-10^{12} \Omega \cdot \mathrm{cm}$ ) while in region of reversible electrical breakdown their resistance is low (of order of $10^{2} \Omega \cdot \mathrm{cm}$ ) $[6,7]$. At parallel connection with load, varistors prevent overvoltage on it $[8,9]$. Protective properties of varistors are determined by the coefficient of protection $\mathrm{k}_{\mathrm{pr}}=$ $\mathrm{U}_{100} / \mathrm{U}_{0,001}$, where $\mathrm{U}_{100}$ and $\mathrm{U}_{0,001}$ are voltages on varistor at currents $100 \mathrm{~A} \cdot \mathrm{cm}^{-2}$ and 1 $\mathrm{mA} \cdot \mathrm{cm}^{-2}$, respectively. In this case protection effectiveness will be the greater the closer to one will be the value of $\mathrm{k}_{\mathrm{pr}}[10]$ that correlates with greater nonlinearity of varistor properties. The protection coefficient is an important parameter of varistors. Its value significantly depends on such factors as homogeneity of ceramic microstructure and electrical conductivity of $\mathrm{ZnO}$ grains which limits the current through punched potential barriers (upper part of varistor VCC) [11]. Therefore high-temperature annealing is most important stage in manufacture of varistors.

At this stage the granular structure of zinc-oxide varistor ceramics is formed and potential barriers responsible for nonlinearity of varistor $\mathrm{VCC}$ arises at $\mathrm{ZnO}$ grain boundaries [12-15]. However, it should be borne in mind that physical-chemical processes occurring during annealing of $\mathrm{ZnO}$ varistor ceramics are largely determined by the gaseous atmosphere composition [16]. This suggests a difference of electrophysical properties for internal and near-surface regions of varistors. The impedance of near-surface layer connected serially with ceramic bulk in electrical circuit should influence on linear and nonlinear properties of varistors. Such layer has black color in contrast to bulk of green color and in further will be called a black layer.

The purpose of this paper is to determine thickness, electrical resistance and electrical capacitance of the black layer which is formed in $\mathrm{ZnO}$ varistor ceramics during hightemperature annealing in oxidizing atmosphere. 


\section{Samples and experimental procedure}

The studied samples of zinc-oxide ceramics for commercial varistors of composition 97,5 mol.\% $\mathrm{ZnO}, 0,5 \mathrm{~mol} . \% \mathrm{Bi}_{2} \mathrm{O}_{3}, 1,0 \mathrm{~mol} . \% \mathrm{Sb}_{2} \mathrm{O}_{3}, 0,5 \mathrm{~mol} . \% \mathrm{Co}_{3} \mathrm{O}_{4}, 0,5 \mathrm{~mol} . \% \mathrm{MnO}_{2}$ are disk-shaped. They were annealed in air for 1 hour at $1520 \mathrm{~K}$ in accordance with the standard technology of varistor manufacturing.

The data of electronic raster microscopy of cross-chipped of annealed varistor disks performed with REM-106I microscope (SELMI, Ukraine) were used for measuring of thickness of the studied black layer.

Capacitance measurements were performed on " $\mathrm{L}$ and $\mathrm{C}$ high-frequency meter E7$9 \mathrm{~g}$ at the frequency of $600 \mathrm{kHz}$. Studied samples initially had a black layer under each of two electrodes. After the measurements electrode surfaces of the samples were grinded for removing the electrodes and black layer. Then electrodes again were created directly on ceramic material and the measurements were repeated. Thus electrical capacitances of varistor samples containing black layer on both electrode surfaces and capacitances of samples without black layer were measured.

Copper was used as electrodes. Copper electrodes were applied to the bases of varistor disks by the electrochemical method according to [17].

The electrical resistance of the black layer was defined from the calculated dependence of varistor sample resistivity on inverse thickness of the sample with using data [16] of measurements of VCC for commercial $\mathrm{ZnO}$ varistors in the region of Ohm's law before and after removing the black layer.

Electrical capacitances of black layers were calculated from the data of capacitance measurements for varistor samples before and after removing the black layer.

\section{Results and discussion}

Internal regions of varistor ceramics are formed by $\mathrm{ZnO}$ single crystals (main phase) and crystallines with structures of pyrochlore $\mathrm{Zn}_{2} \mathrm{Bi}_{3} \mathrm{Sb}_{3} \mathrm{O}_{14}$, spinel $\mathrm{Zn}_{7} \mathrm{Sb}_{2} \mathrm{O}_{12}$ and bismuth oxide $\mathrm{Bi}_{2} \mathrm{O}_{3}$ embedded in three-dimensional network of Bi-enriched amorphous phase [2]. In view of increased oxygen content the black layer is characterized by higher (3-5 times in comparison with bulk) content of spinel phase, tendency to reduce the pyrochlore phase, and insignificant amount or absence of free $\mathrm{Bi}_{2} \mathrm{O}_{3}$ [16]. Cobalt $\mathrm{Co}^{+2}$ dissolved in bulk of $\mathrm{ZnO}$ grains passes into $\mathrm{Co}^{+3}$ state on crystal surface leading to blackening of the near-surface region of the ceramic [16]. Accordingly microstructures of internal and near-surface regions differ as shown in Fig. 1.

In Fig. 1 the black layer on varistor disk surface is visually observed. The bulk part of varistor disk has lighter color. The black layer thickness is different for different points of the surface. The average thickness of black layer is $40 \mu \mathrm{m}$. Taking into account that the minimal thickness of studied varistor samples is about $1 \mathrm{~mm}$, the following ratio can be accepted:

$$
2 L_{l} / L<<1
$$

where $\mathrm{L}_{1}=40 \mu \mathrm{m}$ and $\mathrm{L} \geq 1 \mathrm{~mm}$ are thickness of black layer and studied samples, respectively. 

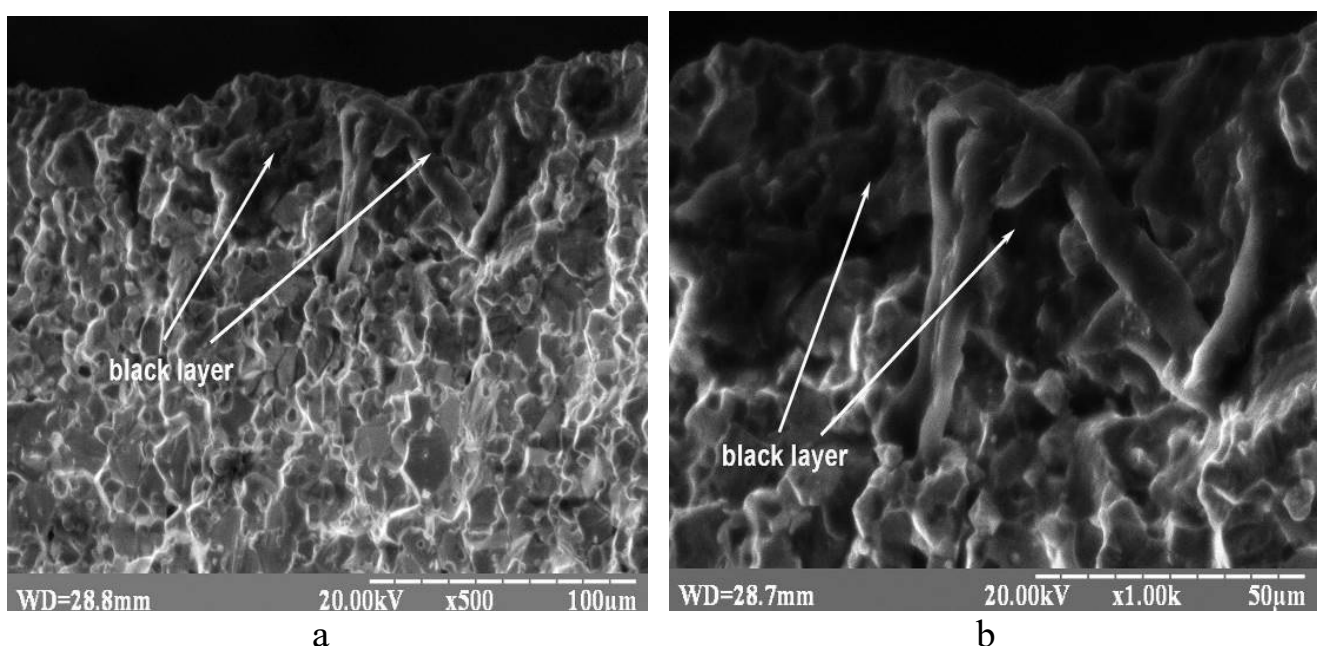

Fig. 1. SEM images of cross-chipped of $\mathrm{ZnO}$ varistor disk annealed in air at magnification of: a) $\times 500$; b) $\times 1000$

An equivalent electrical circuit for a varistor sample containing the studied layer under two electrodes can be represented in a general case by the series connection of impedances as shown in Fig. 2.

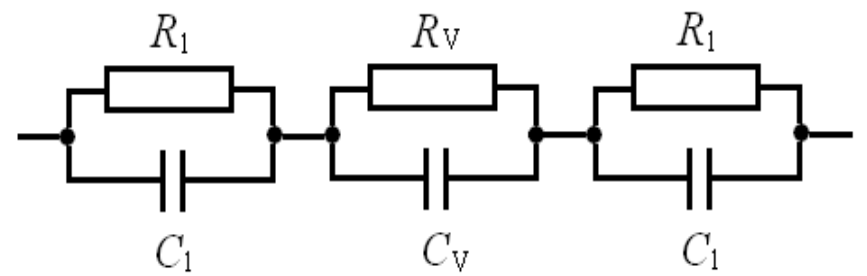

Fig. 2. Equivalent electrical circuit of sample of $\mathrm{ZnO}$ varistor ceramics with black layer under two electrodes: $S_{1}$ and $R_{1}$ - electrical capacitance and active resistance of black layer, respectively; $C_{v}$ and $R_{v}$ - electric capacitance and active resistance of bulk part of studied sample (ceramics), respectively.

At constant current or at very low frequencies the equivalent electrical circuit (Fig. 2) is a serial connection of resistors $\mathrm{R}_{l}$ and $\mathrm{R}_{v}: \mathrm{R}=2 \mathrm{R}_{l}+\mathrm{R}_{v}$, where $\mathrm{R}$ is varistor sample resistance. In this case the specific electrical resistivity $\rho$ of varistor sample, taking into account relation (1), is determined by the following expression:

$$
\rho=\rho_{v}+2 \rho_{l} \frac{L_{l}}{L}
$$

where $\rho_{v}$ is specific electrical resistance of bulk part of sample; $\rho_{l}$ is specific electrical resistance of thestudied black layer.

Expression (2) determines the direct dependence $\rho \sim 1 / L$ shown in Fig. 3.

As follows from expression (2) and Fig. 3, the black layer contribution to varistor resistivity will increase with varistor thickness decreasing.

The specific electrical resistance of the black layer is determined using expression (2) at substituting the measured values of corresponding physical quantities. 


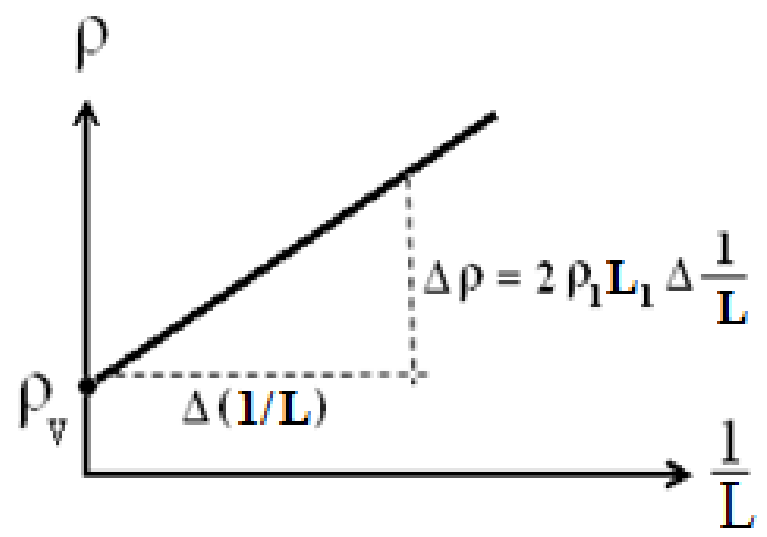

Fig. 3. Calculated dependence of specific electrical resistivity of $\mathrm{ZnO}$ varistor with black layer on electrode surfaces on inverse thickness of the varistor.

Values $\rho$ and $\rho_{v}$ for $\mathrm{ZnO}$ varistor samples in the region of Ohm's law can be found from data of measurements of VCC for commercial $\mathrm{ZnO}$ varistor given in [16].

According to these data, the resistivity of varistor sample with the black layer under two electrodes is $4.0 \cdot 10^{10} \Omega \cdot \mathrm{cm}$. For a varistor with removed black layer the resistivity is significantly lower $-3.5 \cdot 10^{7} \Omega \cdot \mathrm{cm}$. The initial thickness of varistor sample, according to [16], is $0.98 \mathrm{~cm}$.

Value $\rho_{l}$ calculated with using expression (2) is approximately $5.3 \cdot 10^{12} \Omega \cdot \mathrm{cm}$.

The large value of quantity $\rho_{l}$ can be explained by higher intergranular potential barriers in black layer in comparison with varistor bulk [16].

At capacitance measurements at high frequencies the amplitude value of variable voltage applied to a sample is small (not more than $5 \mathrm{~V}$ ) and capacitance conductivity (Fig. 2) exceeds active conductivity. In this case the equivalent electrical circuit shown in Fig. 2 is a serial connection of capacitances $C_{l}$ and $C_{v}$. Taking into account relation (1), electrical capacitance of the black layer can be found from measured at high frequencies capacitances of varistor samples as:

$$
C_{l}=\frac{2 C_{2}}{\frac{C_{2}}{C_{1}}-\frac{L_{1} S_{2}}{L_{2} S_{1}}}
$$

where $C_{2}$ and $\mathrm{C}_{1}$ are electrical capacitances of varistor sample without black layer and with black layer under two electrodes, respectively; $L_{1}$ and $L_{2}$ are thicknesses of varistor sample with black layer under two electrodes and without black layer, respectively; $S_{2}$ and $S_{1}$ are areas of electrodes of varistor sample without black layer and with black layer on two electrode surfaces, respectively.

It follows in particular from (3) that at the initial absence of the black layer (in this case its thickness $L_{l}=0$ and $\left.C_{1} \rightarrow \infty\right) C_{2} / C_{1}=\left(L_{1} S_{2}\right) /\left(L_{2} S_{1}\right)$.

Table 1 shows results obtained from capacitance measurements for samples of $\mathrm{ZnO}$ varistor ceramics before and after removing the black layer by grinding. 
Table 1

\begin{tabular}{|c|c|c|c|c|c|c|c|}
\hline$L_{1}, \mathrm{~mm}$ & $S_{1}, \mathrm{~cm}^{2}$ & $L_{2}, \mathrm{~mm}$ & $S_{2}, \mathrm{~cm}^{2}$ & $C_{1}, \mathrm{pF}$ & $C_{2}, \mathrm{pF}$ & $C_{1}, \mathrm{pF}$ & $\varepsilon_{l}$ \\
\hline 0,92 & 2,34 & 0,73 & 2,40 & 2295 & 3684 & 23567 & 421 \\
\hline 3,82 & 5,30 & 3,38 & 5,20 & 1533 & 1749 & 109153 & 861 \\
\hline 9,80 & 4,00 & 9,20 & 4,74 & 691 & 895 & 54338 & 568 \\
\hline
\end{tabular}

The values of relative permittivity $\varepsilon_{l}$ of the black layer were calculated using values of its thickness $L_{l}$ which previously was found from data of scanning electron microscopy (Fig. 1).

As can be seen from Table 1, the electrical capacitance of the black layer much exceeds the capacitance of the sample itself that contains such layer on two electrode surfaces. This suggests that a black layer does not influence noticeably on nonlinear properties of varistor ceramics. Really, according to data of [16], the VCC for samples with the black layer and without it coincide starting from current densities $10^{-3} \mathrm{~A} \cdot \mathrm{cm}^{-2}$.

\section{Conclusions}

According to data of raster electron microscopy, it is defined that the average thickness of a black layer formed on $\mathrm{ZnO}$ varistor ceramics during its high-temperature annealing is 40 microns. Structure and electrical properties of such layer differ from bulk due to different formation conditions.

From the calculated dependence of the electrical resistance of a varistor in the region of Ohm's law on inverse thickness of the varistor the specific resistivity of its black layer is determined. The value of specific electrical resistivity of black layer is $5.3 \cdot 10^{12} \Omega \cdot \mathrm{cm}$ that is approximately two orders higher than that of varistor sample.

It is found that the electrical capacitance of the black layer calculated from capacitance measurements of varistor samples is more than an order higher than that of sample itself that contains such layer.

Due to the large capacitance connected in series with the capacitance of varistor bulk, the black layer makes a weak contribution to dielectric properties of $\mathrm{ZnO}$ varistor. However, due to high electrical resistivity contribution of such layer to electrical conductivity of a varistor in the pre-breakdown region is significant.

\section{References}

1. Gupta, T.K. Application of zinc oxide varistors / T.K. Gupta // Journal of the American Ceramic Society. - 1990. - Vol. 73, N 7. - P. 1817 - 1840.

2. Li, J.-L. Microstructure and electrical properties of rare earth doped ZnO-based varistor ceramics / J.-L. Li, G.-H. Chen, Ch.-L. Yuan // Ceramics International. - 2013. Vol. 39, N 3. - P. 2231 - 2237.

3. Poosimma, P. Stability of zinc oxide varistors / P. Poosimma // A thesis submitted to the University of Manchester for the degree of Doctor of Philosophy in the Faculty of Engineering and Physical Sciences. - 2014.

4. Zhao, H. Improving age stability and energy absorption capabilities of $\mathrm{ZnO}$ varistors ceramics / H. Zhao, J. Hu, Sh. Chen, Q. Xie, J. He // Ceramics International. 2016. - Vol. 42, N 15. - P. $17880-17883$.

5. Bai, H. Influence of $\mathrm{Bi}-\mathrm{Co}-\mathrm{O}$ synthetic multi-phase on electrical properties of the $\mathrm{Zno}-\mathrm{Bi}_{2} \mathrm{O}_{3}-\mathrm{MnO}_{2}-\mathrm{SiO}_{2}$ varistors / H. Bai, Y. Sun, Zh. Xu, R. Chu, G. Li // Materials Letters. - 2017. - Vol. 209. - P. $115-117$. 
6. Rabab, S. Influence of zinc oxide particle size and surface properties on the electrical, optical and cytotoxicity characteristics of zinc oxide discs / S. Rabab // Thesis submitted in fulfillment of the requirements for the degree of Doctor of Philosophy. University Sains Malaysia. - 2015.

7. Ivon, A. I. Grain resistivity in zinc oxide and tin dioxide varistor ceramics / A. I. Ivon, A. B. Glot, R. I. Lavrov, Zh.-Y. Lu // Journal of Alloys and Compounds. - 2014. Vol. 616. - P. $372-377$.

8. Martzloff, F. D. Surge-Protective Devices / F. D. Martzloff, L. M. Levinson // In book: Electronic Ceramics: Properties, Devices, and Applications (Electrical and Computer Engineering) / Ed. by L. M. Levinson. - New York, 1988. - P. 275 - 305.

9. In-situ quantitative measurement of electric fields in zinc oxide thin films using electrostatic force microscopy // Jan Harloff. - University of Pennsylvania, School of engineering and applied science. - December, 1995. $-85 \mathrm{p}$.

10. Dmitriev, M. V. The use of OPN to protect the insulation of $6-750 \mathrm{kV}$ overhead lines (Применение ОПН для защиты изоляции ВЛ 6-750 кВ) / M. V. Dmitriev. - S. Peterburg.: Politech. University, 2009. - 92 p.

11. Bartkoviak, M. Nonlinear currents in Voronoi networks / M. Bartkoviak, G. D. Mahan // Physical. Review B. -1995. - Vol. 51, № 16.P. 10825 - 10832.

12. Meshkatoddini, M. R. Metal oxide ZnO-based varistor ceramics / M. R. Meshkatoddini // In book: Advances in Ceramics - Electric and Magnetic Ceramics, Bioceramics, Ceramics and Environment / Ed. By C. Sikalidis. - InTech, September 2011. - pp. $329-356$.

13. Clarke, D. R. Varistor Ceramics / D. R. Clarke // Journal of the American Ceramic Society. - 1999. - Vol. 82, № 3. - P. 485 - 502.

14. Beynet, Y. ZnO-based varistors prepared by spark plasma sintering / Y. Beynet, A. Izoulet, S. Guillemet-Fritsch and at. // Journal of the European Ceramic Society. 2015. - Vol. 35, № 4. - P. 1199 - 1208.

15. Katkov, V. F. Electrical conductivity and structure of the near-surface region of oxide-zinc ceramics / V. F. Katkov, A. B. Glot, A. I. Ivon // Neorg Materials. - 1989. V.25, №2. - P. 526 - 528.

16. Patent 98937 Ukraine. Method of forming a metal layer on ceramics / R. I. Lavrov, I. M. Chernenko, A. I. Ivon. - 2012. - Bul. № 13.

17. Lavrov, R. I. Comparative characteristics of silver and copper electrodes on $\mathrm{ZnO}$ varistor ceramics / R. I. Lavrov, A. I. Ivon, I. M. Chernenko // Journal of the European Ceramic Society. - 2003, Vol. 24, № 9. - P. 2591 - 2595. 